\title{
ELECTRONIC HEALTH RECORD SYSTEMS IN THE CLOUD: CRITICAL SUCCESS FACTORS FOR IMPLEMENTATION
}

\author{
Christopher J. Gray, Robert Morris University, cjgst2@mail.rmu.edu
}

\begin{abstract}
The date for healthcare organizations to implement an electronic health record (EHR) system is quickly approaching. As set forth in the Health Information Technology for Economic and Clinical Health (HITECH) Act, every healthcare provider must have an EHR implemented by 2015. Healthcare providers must also demonstrate that they are using the system according to meaningful use standards set forth by the government. If these conditions are met, healthcare providers can share in the $\$ 29$ billion set aside by Medicare and Medicaid. If they fail to implement an EHR system by 2015, they are subject to penalties, and cannot collect any incentive money. Even with these incentives and penalties, small medical practices are lagging behind larger organizations when it comes to implementation. This is due to cost of the system, lack of technical capabilities, and skepticism that EHRs will help improve medical care. Cloud technologies could help overcome cost and technology barriers for these small medical practices. This research was done to answer the question: What are the critical success factors for implementation of an electronic health record system in the Cloud.
\end{abstract}

Keywords: EHR, EMR, cloud, HITECH, critical success factors, Delphi

\section{INTRODUCTION}

The Health Information Technology for Economic and Clinical Health (HITECH) Act was introduced in February 2009 as part of the American Recovery and Reinvestment Act (ARRA). HITECH introduced \$29 billion in incentives for healthcare organizations to adopt electronic health record (EHR) systems [1]. An EHR is a software program that allows healthcare organizations to keep patient medical records in digital format, giving them the ability to share patient records with other medical providers, prescribe medications, and order testing electronically [6]. The incentives were to be paid through Medicare or Medicaid, and were dependent upon the healthcare organization achieving meaningful use with the implemented EHR. Meaningful use indicates that the organization using the EHR is meeting specific usage guidelines set forth by the government in order to increase the level of patient care provided [1]. The potential incentives are $\$ 44,000$ through Medicare or $\$ 63,750$ through Medicaid. Healthcare organizations must have EHR systems implemented by 2015 , or incur a penalty each year after. The penalties would be taking away a percentage of their Medicare and Medicaid reimbursement payments. These penalties include $1 \%$ in 2016, $2 \%$ in 2017, and 3\% for each year after that the organization does not have an EHR in use [9]. By providing incentives for implementation, or penalties for non-compliance, the hope is EHR systems will be implemented by all healthcare organizations.

The goal of the program was to have EHRs implemented in all health organizations by 2015 ; however, this goal may not be achieved. Numerous studies have shown that EHR implementation, especially in small physician practices, has not occurred. According to a study done by Hsiao (2013), physicians in smaller practices are still behind in adoption of EHRs [10]. In 2011 The National Center for Health Statistics (NCHS) performed a study, surveying 5,232 eligible physicians. Of the physicians surveyed, 3,180 responded. The results of the survey showed the following: (1) $55 \%$ of the respondents were adopters of EHR systems; (2) Younger physicians and physicians whose practices were owned by larger health organizations, HMOs, and academic health centers were more likely to adopt EHR systems; (3) Older physicians and physicians who own their own practices were less likely to be EHR system adopters [11]. Another study done by Decker et al. (2012) found smaller practices of only one or two physicians, as well as independently owned practices were less likely to implement an EHR system [4]. These studies all show that EHR adoption has been slower in smaller practices.

The three main reasons for this slow adoption rate may be financial, technical, and pure skepticism concerning EHR systems. According to several studies, return on investment is a major factor when determining to institute an EHR. Small practices are not seeing a return on investment and are deciding to not implement an EHR [17, 25, 5, 23]. Second, practices do not possess the technical capabilities to install and maintain an EHR system [25, 5, 23]. Third, 
numerous studies suggest practices are skeptical about EHR systems effectiveness in providing improved medical care $[15,13,19]$. Overcoming these three objections will help speed the adoption of EHR sytems.

To implement an EHR system, and try to overcome these three obstacles, cloud-based implementations have become a viable option. The National Institute of Standards and Technology (NIST) (2011), defines cloud computing as:

A model for enabling ubiquitous, convenient, on-demand network access to a shared pool of configurable computing resources (e.g., networks, servers, storage, applications, and services) that can be rapidly provisioned and released with minimal management effort or service provider interaction [16].

There are many advantages for small physician practices that choose to implement an EHR system in a cloud-based scenario. According to the Health Information and Management Systems Society (HIMMS) (2012), the advantages of a cloud-based implementation are: (1) A smaller local hardware footprint since much of the hardware needed is housed at the cloud provider; (2) The cloud provider is in charge of making sure there is enough hardware to provide service; (3) Cooling and power are supplied by the cloud provider; (4) Physical security of the facility is normally provided; (5) The cloud provider is in charge of system maintenance [7]. The cloud provider allows the medical practice to concentrate on healthcare, not worry about IT hardware and software.

There have been many studies done concerning EHR implementations and EHR usage, however, none of them dealt with EHR implementations in a cloud-based scenario. Implementing a system using a cloud-based EHR is a viable alternative to traditional local hardware and software-based systems for many small physician practices. This study aims to fill a gap in the literature by finding what factors lead to a successful EHR implementation in a cloud-based scenario.

\section{RESEARCH METHODOLOGY}

A modified Delphi method was used to answer the following research question:

R1: What are the critical success factors for implementing an electronic health record system in a cloud-based scenario?

The Delphi method is a technique originally developed by the RAND Corporation in the 1950s. The technique was designed for use as a group opinion gathering technique. By using multiple rounds of surveys, a researcher is able to gather a group's opinions from experts, or extremely knowledgeable individuals, and refine those opinions into a consensus. What makes this method unique is that the group members stay anonymous; they do not know about each other [3]. According to Norman Dalkey (1967), the main characteristics of the Delphi method are "....anonymity, controlled, feedback, and statistical group response" [3]. Once initial opinions are gathered from the group of experts, multiple survey rounds are used to refine the group's opinions until a consensus is formed. This helps reduce unwanted aspects of group dynamics from introducing bias into the study [3]. By using this method, the researcher was able to virtually gather a diverse group of healthcare and healthcare information technology experts to determine critical success factors for implementation of electronic health record systems in a cloud-based environment.

The researcher was trying to rank the success factors for implementing an electronic health records system in a cloud-based scenario. Therefore, the researcher used a modified Delphi method specifically designed for rankingtype studies, developed by Roy C. Schmidt. The Schmidt Delphi method has three distinct data collection phases: (1) the discovery of issues, (2) determining the most important issues, (3) ranking the issues [20]. A round of semistructured interviews was added after the three rounds in order to validate the findings of the study, as well as answer questions about what may have externally affected the study.

Another factor that makes a Delphi survey different from a traditional survey structure is the use of a small participant pool. Delphi uses a small, representative group of qualified experts; in this case, people knowledgeable about EHR implementation in cloud-based environments. The expert panel for a Delphi study is suggested to 
contain 10 to 18 qualified members [18]. For this study, a diverse group of panelists was used to eliminate bias. However, they all had extensive knowledge of EHR systems in a cloud-based scenario. Due to this extensive knowledge, for the purposes of this study they were considered experts. For this Delphi study there were 24 original participants in the first round, 22 participants in the second round, and 22 participants in the third round. The total number of unique participants, regardless of round, was 25.

Phase one involved gathering information by asking the participants of the study for their opinions. From these opinions a single list was generated [20]. A survey was developed to gather basic demographic information to ascertain if the potential participant matched the criteria necessary to be considered an expert in cloud-based EHR implementations. The survey also asked to describe three to six factors they believed were critical to a successful cloud-based EHR implementation.

Once the surveys were collected, and the final participants selected, the critical success factors listed were put into themes. Duplicate factors were eliminated, and the rest were examined for similarities. If similar answers existed, they were combined into one unique statement. All factors provided were kept as close to their original wording as possible [12]. The panel provided some statements that were deemed multiple success factors. These were split into single success factors and added to the phase one list. These factors were then put into a single list consisting of 88 critical success factors in order to proceed with phase two of the study.

In phase two, participants were asked to choose their top ten critical success factors from the list created from phase one. Twenty-two panelists participated in phase two of the study. From the surveys collected, a new list of factors was generated based on panelist selections. In this case, if a certain percentage of the panel members choose a critical success factor from the list, what was termed consensus, then that factor was added to the third phase survey [20]. In order to achieve consensus, a factor must have been picked by $50 \%$ of the panel members.

Factors under a 50\% consensus level that received votes were re-evaluated at the end of phase two. This was done due to the possibility that the combining and elimination of factors during phase one could have been more thorough. If the factor was chosen by a panel member in phase two, but did not receive $50 \%$ consensus amongst the panel, it was reviewed. If reviewed statements could be combined, and it took the statement above $50 \%$ consensus, the combined statement was added to phase three. For example, the critical success factor "EHR Training Implementing a strong training / education process for EHR users" was created by combining the seven factors under the training theme. During phase two, all seven factors received votes, but only one reached a $50 \%$ consensus level. Therefore, the factors were combined into one representative statement.

Other factors were added to phase three based upon the literature review, even if they did not achieve consensus. The factors "High-level security" and "Cost effective, reasonably priced solution that gives providers an affordable solution as an alternative to having to purchase hardware equipment" were both added to phase three based upon the literature review.

Phase three was used to ask the panel members to rank their top twenty critical success factors from the final list generated from phase two in order of importance. Once the data was collected, it was analyzed using Kendall's W, also called Kendall's coefficient of concordance, which “...can be used to assess the degree to which a group of variables provides a common ranking for a set of objects" [14]. For this study, Kendall's W was used to determine if the panel members agreed on critical success factor rankings. Other factors used to analyze the final rankings of critical success factors were the following: (1) the percentage of panel members who chose the factor within the top ten; (2) the percentage of panel members who chose the factor within the top twenty; (3) the statistical mean for the ranking of the success factor.

To validate the critical success factors and the results of the three phase Delphi study, three semi-structured interviews were performed. Gregory Skulmoski, Francis Hartman, and Jennifer Krahn (2007), state "For Ph.D. research conducted in our program, the Delphi results are often extended with a subsequent research phase such as interviews or surveys" [24]. The participants of the interviews represented a healthcare organization, an EHR software vendor, and a health IT consulting firm. The first interviewee was a general manager of a health IT consulting firm, the second interviewee was from a leading EHR software vendor, and the third interviewee was the practice manager for an independent sports medicine practice. 


\section{RESULTS}

After three Delphi phases, the top twenty critical success factors for a cloud-based implementation of an electronic health record (EHR) system were established. Table 1 shows the top twenty critical success factors for phase three of the study. The table has two columns, one for the success factor and one for the numerical identifier of each success factor.

Table 1

\begin{tabular}{|c|l|}
\hline$\#$ & \multicolumn{1}{|c|}{ Critical Success Factors } \\
\hline 2 & EHR training - Implementing a strong training / education process for EHR users \\
\hline 3 & High-level security \\
\hline 5 & $\begin{array}{l}\text { Cost effective, reasonably priced solution that gives providers an affordable solution as an alternative } \\
\text { to having to purchase hardware equipment }\end{array}$ \\
\hline 6 & Support services such as deployment / implementation services, help desk, and online support \\
\hline 7 & Experienced Consultants / Supportive Vendor \\
\hline 11 & Customization of EHR product to reflect workflow and medical specialty \\
\hline 12 & $\begin{array}{l}\text { Strong clinical representation in the project to ensure workflows, processes and education needs are } \\
\text { met }\end{array}$ \\
\hline 15 & $\begin{array}{l}\text { Physician Champion - understand technology and how to leverage for practicing medicine (including } \\
\text { regulation). The champion makes the best implementation decision and 'persuades' other physicians } \\
\text { and staff }\end{array}$ \\
\hline 17 & $\begin{array}{l}\text { Having a strong process in place to test, build, implement functionality that includes a way to track } \\
\text { changes and distribute the changes to key personnel }\end{array}$ \\
\hline 18 & Strong application support / technical support \\
\hline 20 & Ease of access and availability of the system \\
\hline 21 & Speed of the system - performance \\
\hline 22 & User Friendliness \\
\hline 23 & $\begin{array}{l}\text { Ability to document accurately for EHR incentives and to satisfy outside auditors (i.e., The Joint } \\
\text { Commission, state license auditors, insurance providers) }\end{array}$ \\
\hline 25 & Ability to connect with outside services or resources (lab interfaces, immunization registries, etc.) \\
\hline 26 & $\begin{array}{l}\text { Anytime/anywhere access - Allow users to access their EHR from anywhere reliably without having } \\
\text { to be in their office }\end{array}$ \\
\hline 30 & Usability- practical application of EHR features in a real medical office setting \\
\hline 31 & Performance - solution must be 'fast' for the end user \\
\hline 32 & Stable - solution must perform consistently \\
\hline 33 & $\begin{array}{l}\text { Reliability - Specifically high levels of redundancy and system availability. If the system is down, } \\
\text { patient safety is a risk, and that is an unacceptable norm. }\end{array}$ \\
\hline
\end{tabular}

For the study, the top ten critical success factors were the following:

1. Factor 2 - EHR training - Implementing a strong training / education process for EHR users

2. Factor 30 - Usability- practical application of EHR features in a real medical office setting

3. Factor 33 - Reliability - Specifically high levels of redundancy and system availability

4. Factor12 - Strong clinical representation in the project to ensure workflows, processes and education needs are met

5. Factor 6 - Support services such as deployment / implementation services, help desk, and online support

6. Factor 18 - Strong application support / technical support

7. Factor 15 - Physician Champion - understand technology and how to leverage for practicing medicine (including regulation). The champion makes the best implementation decision and 'persuades' other physicians and staff

8. Factor 21 - Speed of the system-performance

9. Factor 22 - User Friendliness

10. Factor 20 - Ease of access and availability of the system 
Factor 9 - "Attitude- understanding and committing to a successful EHR transition", did not make the top 20 success factors. However, it was the factor that received the most number one (1) rankings during the study with six panel members ranking this factor first.

Table 2 shows the data collected from phase three of the study. The first column designates the identifier assigned to the corresponding critical success factor. The second column is the number and percentage of panelists that chose that factor as a top twenty success factor. The third column is the number and percentage of panelists that chose that factor as a top ten success factor. The fourth column represents the mean, or average, ranking for the success factor.

Table 2

\begin{tabular}{|l|l|l|l|}
\hline Factor ID & Picked in the Top 20 & Picked in the Top 10 & Mean \\
\hline 2 & $20(90.91 \%)$ & $11(50.00 \%)$ & 10.3 \\
\hline 30 & $18(81.82 \%)$ & $10(45.45 \%)$ & 10.17 \\
\hline 33 & $17(77.27 \%)$ & $13(59.09 \%)$ & 6.88 \\
\hline 12 & $17(77.27 \%)$ & $11(50.00 \%)$ & 8.94 \\
\hline 6 & $17(77.27 \%)$ & $8(36.36 \%)$ & 12.29 \\
\hline 18 & $16(72.73 \%)$ & $8(36.36 \%)$ & 10.63 \\
\hline 15 & $15(68.18 \%)$ & $9(40.91 \%)$ & 8.07 \\
\hline 21 & $15(68.18 \%)$ & $10(45.45 \%)$ & 8.4 \\
\hline 22 & $15(68.18 \%)$ & $9(40.91 \%)$ & 9.8 \\
\hline 20 & $15(68.18 \%)$ & $6(27.27 \%)$ & 11.13 \\
\hline 3 & $14(63.64 \%)$ & $7(31.82 \%)$ & 11.71 \\
\hline 26 & $14(63.64 \%)$ & $1(4.55 \%)$ & 14.5 \\
\hline 32 & $13(59.09 \%)$ & $11(50.00 \%)$ & 7.38 \\
\hline 11 & $13(59.09 \%)$ & $5(22.73 \%)$ & 11.85 \\
\hline 7 & $13(59.09 \%)$ & $4(18.18 \%)$ & 12.38 \\
\hline 5 & $12(54.55 \%)$ & $7(31.82 \%)$ & 7.17 \\
\hline 25 & $12(54.55 \%)$ & $6(27.27 \%)$ & 11.17 \\
\hline 31 & $12(54.55 \%)$ & $3(13.64 \%)$ & 11.92 \\
\hline 23 & $12(54.55 \%)$ & $3(13.64 \%)$ & 13.17 \\
\hline 17 & $12(54.55 \%)$ & $3(13.64 \%)$ & 13.42 \\
\hline
\end{tabular}

Interviews were conducted to validate the survey results, as well as gather opinions on why factor ranking consensus was not achieved. Interviewee one (2014) identified the following critical success factors: (1) staff participation and attitude; (2) a strong office manager and project champion; (3) training; (4) the office IT infrastructure; (5) Internet connections and speed; (6) workflow. The following statements were taken from interviewee one (2014) during the interview:

(1) A lot of it has to do, in my opinion, with the staff itself. They have to be willing to participate. They have to have a good attitude about it.

(2) You have to have a strong office manager. That's just crucial. It's important to make it go. They have to keep doing it too.

(3) Without training, our clients not going to succeed. In my opinion, I'm not saying that our clients' not smart enough to try and figure it out but you learn bad habits, you'll learn ... Maybe you're doing things within the EMR that aren't the best way for you to do it or you're taking five steps to do something, we can simply show you in two steps but you don't know that because you won't let us train. 
(4) Definitely speed. We can make a Cloud-based system as quick as we can make a client server, which in reality we will probably never can because it is a different technology but speed is a big thing. That is the biggest thing when we implement that we do have to watch, we have to make sure that they understand that and we have to try and set realistic expectations.

(5) Obviously, your network being set up correctly, if you're a client server or making sure you have all the necessary components in place, be properly set up in a data center that IT piece of it is important as well. You've got the proper speeds, you've got the proper connections.

(6) We go through the training process pretty much the same and we do a work flow assessment and we have everybody fill out a work flow assessment so we can get a feel for how the office works and who the key players are and what those people's roles are. Obviously asking questions specifically about what the doctors do for their encounters so we have an idea of how to personally work with them.

Interviewee two (2014) identified the following critical success factors during the interview: (1) reliability; (2) ease of use; (3) training. The following statements were taken from interviewee two (2014) during the interview:

(1) Well, for the first one for the reliable pipeline the Internet connections speed and uptime; that was important to me because for many reasons. One is if you can't use the product in real time without gaps people get frustrated. If it's constantly going down you're going back to your old system or to paper.

(2) It's easier to train in an environment that's up and has no issues and no interruptions so that people can actually get a feel for it real time and use it real tine and not be frustrated, aggravated, adding to an already stressful situation.

(3) If your computers aren't able to process and function properly and if the network it's able to handle what's happening to it, the data that's flowing through it, you're going to have frustration on the end-user level. The less frustration on the end-user level that you have, the better your implementation is going to go because they're not constantly worried about having to click and wait, having patients wait longer. It's just having the appropriate systems and network and function at a good speed is necessary.

(4) Training of staff, naturally knowledge is power. If somebody can resolve an issue on their own without having to take time, stop what they're doing and pull somebody else in, which that person may be on the phone, maybe not in. If they can fix something on their own, It gives them a sense of power, it gives them a sense of okay I can get this fixed and get about my day.

(5) Backup Internet connections or power source for the network, again, all that stuff is just connection related. Making sure where we have the most up time possible and the least interruption to service because we're busy. We like to keep moving. Anything that slows us down is a nuisance and an aggravation and creates tensions.

These factors gathered from the three interviewees matched the top factors obtained from the Delphi survey process.

\section{CONCLUSIONS}

There were several themes that emerged through the study. The first is that an implementation is considered successful if the EHR system can be used effectively. The second theme was the need for training. This theme directly relates to the usability of the system. The third was that implementation success is all based upon individual user perception. The fourth theme that emerged was a project champion is needed for implementation success. The fifth theme is that cost did not play a larger role in determining implementation success. The final theme was the fact that the success factors discovered could apply to both cloud-based and local EHR system implementations. These themes are discussed below. 


\section{Usability}

System usability emerged as one of the major themes of the study. Usage of the system, or reasons why the systems might be used within the practices, was not the aim of the study. However, it is evident that successful system usage following the implementation creates a perception of a successful implementation. It can be argued that eight of the top ten critical success factors gathered during the study dealt with using the EHR after implementation, and did not necessarily deal with implementation itself..

\section{Training}

The panel members chose factor 2 - "EHR training - Implementing a strong training / education process for EHR users" as the number one critical success factor for cloud-based EHR implementations. Twenty panel members ranked this critical success factor within the top 20 . That is over $90 \%$ of the participants within the study. Training during an EHR implementation is directly linked to the actual usage of the system. For the users to accept the new system, and for them to believe the implementation was successful, they must be able to use the system effectively after implementation. Training leads to successful system usage.

\section{Perceptions}

One of the interesting findings of the study was the lack of agreement amongst the panel members for the ranking of the factors. There was consensus on which factors were ranked within the top twenty and within the top ten. However, there was no consensus to where within the top twenty, or top ten, the factors were ranked. For example, even though factor 2 - "EHR training - Implementing a strong training / education process for EHR users" was picked by the most number of panel members within the top twenty, there was no consensus on whether it was ranked first or twentieth most important. Also, factor 9 - "Attitude- understanding and committing to a successful EHR transition" received the most number one rankings amongst the panel, but did not achieve $50 \%$ consensus as a top twenty critical success factor.

The three individuals interviewed were not surprised by this finding. They felt that the original panel was very diverse, and this is what led to the lack of ranking consensus for the study. Each individual panel member was viewing critical success factors from their frame of reference, or perspective. A hospital administrator may have a different point of view from an EHR software vendor or a small physician practice office manager. Also, some panel members may be more technically savvy, or they may have implemented multiple EHRs, giving them more experience with the process. The interviewees felt individual perception played a large role in the lack on ranking consensus.

Another phenomenon that may have played a role in the lack of consensus was the location of the study. Interviewees saw this as another reason that ranking consensus was not achieved. The study was performed in western Pennsylvania. Twenty of the panel members were from organizations within western Pennsylvania. Interviewees believed that the ongoing legal issues between the two largest healthcare providers in the area, Highmark and the University of Pittsburgh Medical Center (UPMC) may have affected the study. Traditionally, Highmark is a medical insurance provider and UPMC is a medical care provider. The two entities have a contract with each other that is set to expire in 2014.

UPMC and Highmark have each ventured into the other's core business. UPMC has created a health insurance company, while Highmark and Western Pennsylvania Health Systems have joined to create Allegheny Health Network (AHN). Both are building new medical facilities, while also acquiring existing healthcare facilities [2]. The medical community in western Pennsylvania is waiting for the outcome of this situation, and this has potentially caused EHR adoption to be slower.

\section{Project champion}

Organizations implementing a cloud-based EHR system need a strong champion within the organization. According to Kathy Schwalbe (2010), "Some projects have a senior manager called a champion who acts as a key proponent for a project. The sponsor can serve as a champion, but often another manager can more successfully take on this 
role" [22]. During the validation interviews, it was stated, "You have to have a strong office manager. That's just crucial. It's important to make it go. They have to keep doing it too". A medical practice needs a project champion for an EHR implementation to be successful.

\section{Cost}

Cost of the system was ranked within the top twenty success factors for implementation. However, it was surprising that cost was not ranked higher. Through the literature review, cost was a main concern for medical because they did not see a return on investment from the purchase and usage of an EHR. The Delphi panel ranked cost as the sixteenth most critical success factor for EHR implementations in a cloud-based environment. This seems to be in complete contrast to the literature review and previous studies done concerning adoption of EHR systems.

\section{Cloud-specific findings}

Of the top twenty critical success factors for cloud-based EHR implementations, not one factor could specifically be pointed to as cloud specific. All of the factors found could apply to a cloud-based implementation, as well as a local system implementation. An example of a cloud specific success factor would be a practice's Internet connection speed, or the reliability of the Internet connection. However, there were no critical success factors that dealt with only cloud-based implementations. The critical success factors found in the study can be applied to all EHR implementations.

\section{SUMMARY}

In summary, the research found that critical success factors for electronic medical record systems in the Cloud centered on the usage of the system. If the system could be used effectively after implementation, the project was considered successful. The research also found perception played a large role in the outcome of the study. Further research, including a larger survey process using the critical success factors found as a base, is suggested.

\section{REFERENCES}

1. Blumenthal, D. (2011). Wiring the health system - origins and provisions of a new federal program. New England Journal of Medicine, 365(24), 2323-2329. Retrieved from http://www.nejm.org/doi/full/ 10.1056/NEJMsr1110507

2. Brino, A. (2013). UPMC continues battle with highmark. Healthcare Finance News. Retrieved from http://www.healthcarefinancenews.com/news/upmc-continues-battle-highmark

3. Dalkey, N. (1967). Delphi, 1-10. Retrieved from RAND Corporation website: http://www.rand.org/pubs/papers/ P3704.html

4. Decker, S. L., Jamoom, E. W., Sisk, J. E., (2012). Physicians in nonprimary care and small practices and those age 55 and older lag in adopting electronic health record systems. Health Affairs, 31(5), 1108-1114. doi: 10.1377/hlthaff.2011.1121

5. DesRoches, C. M., Campbell, E. G., Roa, S. R., Donelan, K., Ferris, T. G., Jha, A., Rosenbaum, S., Shields, A. E., \& Blumenthal, D. (2008). Electronic health records in ambulatory care - a national survey of physicians. The New England Journal of Medicine, 359(1), 50-60. doi: 10.1056/NEJMsa0802005

6. Garrett, P., \& Seidman, J. (2011). EMR vs EHR - what is the difference?. Retrieved from: http://www.healthit.gov/buzz-blog/electronic-health-and-medical-records/emr-vs-ehr-difference/

7. Health Information and Management Systems Society. (2102). Cloud security toolkit: Cloud security 101. Retrieved from http://www.himss.org/files/HIMSSorg/content/files/ PrivacySecurity/ CS03_Cloud_Security_101.pdf

8. HealthIT.gov. Retrieved from: http://healthit.hhs.gov/portal/server.pt/community/healthit_hhs_gov_onc/1200

9. HealthIT.gov. Retrieved from: http://www.healthit.gov/providers-professionals/faqs/are-there-penaltiesproviders-who-don $\% \mathrm{E} 2 \% 80 \% 99 \mathrm{t}$-switch-electronic-health-reco

10. Hsiao, C., Jha, A. K., King, J., Patel, V., Furukawa, M. F., Mostashari, F. (2013). Office-based physicians are responding to incentives and assistance by adopting and using electronic health records. Health Affairs. 32(8), 1470-1477. doi: 10.1377/hlthaff.2013.0323 
11. Jamoom, E., Beatty, P., Bercovitz, A., Woodwell, D., Palso, K., \& Rechtsteiner, E. (2012). Physician adoption of electronic health record systems: United States, 2011. NCHS Data Brief, 98, 1-7. Retrieved from the Center for Disease Control and Prevention website: $\mathrm{http} / / \mathrm{www} . c d c . g o v / \mathrm{nchs} /$ data/databriefs/db98.htm

12. Keeney, S., Hasson, F., \& McKenna, H. (2011). The Delphi technique in nursing and health research. West Sussex, United Kingdom: Wiley-Blackwell.

13. Keyhani, S., Hebert, P. L., Ross, J. S., Federman, A., Zhu, C. W., \& Siu, A. L. (2008). Electronic health record components and the quality of care. Medical Care, 46 (12), 1267-1272. doi: 10.1097/MLR.0b013e31817e18ae

14. Legendre, P. (2010). Coefficient of Concordance. Encyclopedia of Research Design, Vol. 1 (pp. 164-169). Los Angeles, CA: Sage Publications, Inc.

15. Linder, J. A., Ma, J., Bates, D. W., Middleton, B., \& Stafford, R. S. (2007). Electronic health record use and the quality of ambulatory care in the United States. Archives of Internal Medicine, 167(13), 1400-1405. doi:10.1001/archinte.167.13.1400

16. Mell, P., \& Grance, T. (2011). The NIST definition of cloud computing: Recommendations of the National Institute of Standards and Technology (Special Publication 800-145). Retrieved from National Institute of Standards and Technology U.S Department of Commerce website: www.nist.gov

17. Miller, R. H., West, C., Brown, T. M., Sim, I., \& Ganchoff, C. (2005). The value of electronic records in solo or small group practices. Health Affairs, 24(5), 1127-1137. doi: 10.1377/hlthaff.24.5.1127

18. Okoli, C., \& Pawlowski, S. D. (2004). The delphi method as a research tool: an example, design considerations and applications. Information and Management, 42, 15-29. doi: 10.1016/j.im.2003.11.002

19. Romano, M. J., \& Stafford, R. S. (2011). Electronic health records and clinical decision support systems: impact on national ambulatory care quality. Archives of Internal Medicine, 171(10), 897-903. doi: 10.1001/archinternmed.2010.527

20. Schmidt, R. C. (1997). Managing Delphi surveys using nonparametric statistical techniques. Decision Sciences, 28(3), 763-774. doi: 10.1111/j.1540-5915.1997.tb01330.x

21. Schmidt, R., Lyytinen, K., Keil, M., \& Cule, P. (2001). Identifying software project risks: an international delphi study. Journal of Management Information Systems, 17(4), 5-36. Retrieved from http://reddog.rmu.edu:2056/docview/218924388/ 4D1BA57EA287410CPQ/1?accountid=28365

22. Schwalbe, K. (2010). Information technology project management (6th ed.). Boston, MA: Course Technology.

23. Schweitzer, E. J. (2011). Reconciliation of the cloud computing model with US federal electronic health record regulations. Journal of the American Medical Informatics Association, 19, 161-165. doi: 10.1136/amiajnl-2011000162

24. Skulmoski, G. J., Hartman, F. T., \& Krahn, J. (2007). The delphi method for graduate research. Journal of Information Technology Education, 6, 1-21. Retrieved from http://www.jite.org/ documents/Vol6/JITEv6p001021Skulmoski212.pdf

25. Spruell, J., Vicknair, D., \& Dochterman, S. (2010). Capturing the financial benefits of electronic medical record investments in the small medical practice. Journal of Business and Economic Research, 8(6), 85-95. Retrieved from http://reddog.rmu.edu:2056/docview/ 516333453/abstract/6FF714E1C0CB4668PQ/1 ?accountid=28365 